\title{
Lacrimal Gland Carcinoma
}

National Cancer Institute

\section{Source}

National Cancer Institute. Lacrimal Gland Carcinoma. NCI Thesaurus. Code C6129.

A carcinoma that arises from the lacrimal glands. Representative examples include adenocarcinoma, carcinoma ex pleomorphic adenoma, squamous cell carcinoma, adenoid cystic carcinoma, and mucoepidermoid carcinoma. 